\title{
The Effect of Box Height during Drop Landing on Risk Factors of Anterior Cruciate Ligament Injury in Female Players
}

\author{
Sunghe $\mathrm{Ha}^{1,2}$, Sang-Kyoon Park ${ }^{2 *}$ \\ ${ }^{'} Y o n s e i$ University, Seoul, Korea \\ ${ }^{2}$ Korea National Sport University, Seoul, Korea
}

Received: May 30, 2018

Accepted: July 17, 2018

Published online: July 31, 2018

\section{Keywords:}

Anterior cruciate ligament

Biomechanics

Electromyography

Landing

Female soccer players
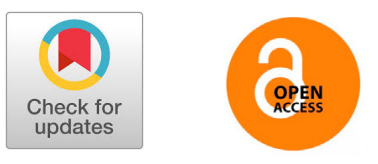

\begin{abstract}
OBJECTIVES This study investigated biomechanical risk factors of the anterior cruciate ligament (ACL) injury as well as muscle activation patterns in the lower extremity according to the increase of box height in female soccer players.

METHODS Twenty-three professional female soccer players participated in this study. Thigh muscle activation patterns, knee joint kinematics, and kinetics were analyzed during drop landing from $30 \mathrm{~cm}$ and $50 \mathrm{~cm}$. Statistical analysis was carried out with a paired t-test to compare the risk factors of anterior cruciate ligament damage in the population with increasing box height.

RESULTS The activation of anterior part of thigh was significantly increased in drop landing from $50 \mathrm{~cm}$ compared with $30 \mathrm{~cm}$, but no significant posterior part. As the box height increased, protective mechanisms of $A C L$ injury were observed increasing $A C L$ injury risk in drop landing.

CONCLUSIONS The hamstring training to maintain stability of the knee joint and limit anterior translation of the tibia may diminish risk of the anterior cruciate ligament injury.
\end{abstract}

(c) The Asian Society of Kinesiology and the Korean Academy of Kinesiology
서론

여성 축구선수의 전방십자인대 손상은 대부분 비접촉 성으로 발생되며[1] 점프 후 착지, 감속 또는 방향 전환 시 나타나는 것으로 보고되고 있다[2]. 안전한 착지를 위해서 는 감각수용기 정보와 낙하높이 및 바닥상태에 대한 상황 인지를 통해 발생될 외력인 지면반력을 예측하고 필요한 근육 동원의 시기 및 활성도를 조절하게 된다[3]. 전방십 자인대 손상은 고유수용감각 정보의 결함을 유발하며 이

*Correspondence: Sang-Kyoon Park, Department of Physical Education, Korea National Sport University, Yangjaedaero 1239, Seoul, 05541 Korea

E-mail: spark@knsu.ac.kr
는 관절의 불안정성을 야기시킴으로 반드시 수술적 또는 비수술적 치료가 요구되는 치명적인 손상이다[4].

무릎관절의 안정성에 중요한 역할을 하는 전방십자인 대는 경골 앞쪽에서 외측 대퇴과의 내측면에 부착되어 대 퇴골과 경골을 이어준다. 경골의 과도한 전방전위에 저항 하고, 완전한 무릎관절의 신전과 과도한 외반, 그리고 축 회전에 저항한다. 이와 함께 무릎을 지나가는 근육들 중 햄스트링은 좌골결절에 기시하여 경골의 후면과 비골두 에 정지하는 근육으로 발이 지면에 닿아 있을 때 대퇴분절 을 기준으로 근위부 하퇴가 전방으로 전위되는 것을 막아 준다 $[5,6]$. 그러나 여성선수의 착지동작은 햄스트링의 활 성이 대퇴사두근에 비해 미약하여 전방십자인대에 장력 을 증가시킨다고 보고된다[7-9]. 햄스트링의 적절한 근동 원은 대퇴사두근과 동시 수축 시 전방십자인대의 장력을

(1) \$ This is an open-access article distributed under the terms of the Creative Commons Attribution License (http://creativecommons.org/licenses/by-nc/4.0/), which permits unrestricted use, distribution, and reproduction in any medium, provided the original work is properly cited.

24 | The Asian Journal of Kinesiology 
감소시킬 수 있으므로 손상예방을 위해서는 햄스트링 강 화가 중요하다고 보고된다[10].

적절하지 못한 하지근육의 동원은 하지의 착지 전략에 영향을 미치게 된다. 여성선수의 경우 점프 후 착지할 때 남성에 비해 무릎관절의 굴곡각이 작게 관찰되었고[7], 경골의 전방 전단력과 외반모멘트는 더 크게 나타나 전방 십자인대손상 위험을 증가시킨다고 보고되었다[11-13]. 또한 Yeow 등은 무릎 굴곡각 감소와 수직지면반력의 증 가는 전방십자인대 손상의 고 위험요인이라고 보고하였 다. 부적절한 근동원은 착지전략의 오류를 유발하게 되어 [14], 박스높이 증가 시 대퇴사두근 근활성만의 증가는 전 방십자인대 손상의 위험요인을 증가시킬 것이라고 보고 되었다[14]. 이와 같이 환경변화에 따른 하지근 동원형태 및 운동역학적 특징을 제시한 연구는 진행되었으나 이를 방어기전으로써 역학적 위험요인과의 연관성을 살펴본 연구가 미흡한 실정이다.

종합해보면 관절의 부하가 높은 동작에서 햄스트링의 동원능력이 떨어지는 여성선수들의 작은 무릎 굴곡각도 는 전방십자인대가 파열 되는 위험이 높게 보고되고 있다. 따라서 손상의 위험수준이 증가함에 따라 하지의 근 동원 형태의 분석을 통하여 인체가 어떻게 위험 상황에 반응하 는가를 방어기전으로써 이해하는 것이 전방십자인대 손 상예방에 필요하다고 사료된다. 본 연구의 목적은 여성 축구선수를 대상으로 박스높이 증가에 따른 하지 근육의 반응형태와 운동역학적 요인의 변화를 관찰하는 것이다.

\section{연구 방법}

\section{연구대상}

본 연구의 대상자는 대한축구협회에 등록된 건강한 엘 리트 여성축구선수 23 명(신장: $165.5 \pm 5.0 \mathrm{~cm}$, 체중: $58.0 \pm 5.3$ $\mathrm{kg}$, 나이: $24.4 \pm 3.8 \mathrm{yrs}$, 경력: $12.1 \pm 2.8 \mathrm{yrs}$ )이 참여하였다. 모 든 대상자는 최근 6 개월간 하지 근골격에 부상을 입은 경 험이 없는 주동측 발이 오른쪽인 여성선수로 선정하였다. 모든 대상자는 자료수집 전 실험절차에 대한 설명을 충분 히 숙지한 후, 자발적으로 참가에 동의한 선수에 한해 동 의서 작성 후 실험을 진행하였다.

\section{실험절차}

대상자는 충분한 준비운동과 3 회 박스 착지 연습 후 동 작분석을 위해 골반과 우측 하지에 25 개의 반사마커를 부
착하였다. 근전도 측정을 위해서는 측정 전 모근과 피부 각질 등을 제거하고 우측 하지의 내측광근(vastus medialis oblique, $\mathrm{VM}$ ), 외측광근(vastus lateralis oblique, $\mathrm{VL}$ ), 대 퇴이두(biceps femoris, $\mathrm{BF}$ )에 전극(FIAB, Italy)을 부착하였 다[16].

$30,50 \mathrm{~cm}$ 높이의 박스에서 착지동작을 수행하기 위해 박스에 올라가 양팔을 가슴에 엇갈려 올려놓고 자연스럽 게 두발로 동시에 점프하여 양발을 각각의 지면반력기 중 앙에 착지하도록 하였다. 각 10 회씩 실시하였고, 피로가 연구변인에 영향을 미치지 않도록 실험 중 대상자에 게 충 분한 휴식을 취하도록 하였다. 박스높이는 무작위로 배정 (randomized order) 하였고, 박스와 지면반력기 사이거리 는 $30 \mathrm{~cm}$ 로 설정하였다[17]

\section{자료처리}

운동학, 운동역학적 위험요인와 근전도 분석을 위해 적외선카메라 8대(Oqus300, Qualisys, Sweden, $250 \mathrm{~Hz}$ )와 지 면 반력기 2대(Type 9286AA, Kistler, Switzerland, 2,500Hz), 무선근전도(Zero-wire EMG, aurion, Italy, 2,500Hz)를 이용 하여 자료를 획득하였다. 위치데이터는 Butterworth 2nd bi-direction 저역통과필터를 이용하여 스무딩하였고, 이 때 차단 주파수(cut-off frequency)는 $12 \mathrm{~Hz}$ 로 설정하였다 [18]. 지면반력은 차단 주파수 $100 \mathrm{~Hz}$ 로 저역통과필터 하 였다[19]. 근전도는 $20 \mathrm{~Hz}-450 \mathrm{~Hz}$ 로 Band-pass filter 후 정류 (rectify)하였고, Moving RMS 20ms으로 스무딩하였다[20]. 적외선 카메라와 지면 반력기, $\mathrm{EMG}$ 의 동조는 적외선 카 메라와 A/D board 간 internal trigger 케이블을 연결하여, QTM(Qualisys Track Manager, Qualisys, Sweden) 소프트웨 어로 통제하였다.

이벤트 설정은 초기 착지 $50 \mathrm{~ms}$ 전 시점(Event $0, \mathrm{E} 0$ ), 지 면반력데이터 최저 한계치를 $20 \mathrm{~N}$ 으로 설정하고 그 이상 의 값이 나오는 시점을 초기 착지시점(Event $1, \mathrm{E} 1$ ), 최대지 면반력시점(Event 2, E2), 최대무릎굴곡시점(Event 3, E3) 으로 구분하였고, 구간 1 은 $\mathrm{E} 0$ 과 $\mathrm{E} 1$ 사이(Phase 1, P1), 구간 2는 E1과 E2 사이(Phase 2, P2), 구간3은 E2와 E3 사이(Phase $3, \mathrm{P} 3)$ 로 설정하였다

\section{분석변인}

Visual3D v3(C-motion, USA) 소프트웨어 내에서 무릎 관절의 3 차원 관절각(degree), 관절모멘트 $(\mathrm{Nm} . / \mathrm{kg})$, 시상 면에서의 관절파워 $(\mathrm{W} / \mathrm{kg})$, 수직지면반력 $(\mathrm{BW})$ 을 산출하 
였다. 관절각을 제외한 모든 값은 상호비교를 위해서 체 중으로 나누어 표준화하였다.

근활성도는 $50 \mathrm{~cm}$ 착지동안 근활성 최댓값을 $100 \%$ 로 기준하고 착지 시의 각 근육의 활동량을 산출하여 상대적 인 근활성의 활동수준(\%MVC)을 표현하였다 $[15,21]$. 표 준화된 근활성도는 다시 대퇴사두근에 대한 햄스트링의 활동 비율(HQratio)을 산출하였다(내측광근에 대한 대퇴 이두근의 비율: HVMratio, 외측광근에 대한 대퇴이두근 의 비율: HVLratio).

\section{HVMratio $=$ norBF/norVM}

HVLratio $=$ norBF $/$ norVL

norBF=Normalized biceps femoris activation (\%MVC)

norVM=Normalized vastus medialis oblique activation (\%MVC)

norVL $=$ Normalized vastus lateralis oblique activation (\%MVC)

모든 변인은 대상자들의 주동측인 우측 무릎관절과 대 퇴근만 분석되었다[14].

\section{통계처리}

박스의 높이가 증가함에 따라 착지동안 주동측 하지 근활성, 무릎관절각, 무릎관절 모멘트, 무릎관절파워, 수직지면반력의 차이를 검증하기 위해 대응표본 $\mathrm{t}$-검정 (Paired t-test)을 실시하였다. SPSS 18.0(PASW statistics 18, IBM, USA)을 사용하였고 가설검증을 위한 유의도 수준 은 $\alpha=.05$ 로 설정하였다. 자료수집 중 착지동작에서 3 명의 Electrode가 떨어져 EMG분석은 20명의 자료만 사용하였 다.

\section{결과}

박스높이에 따른 운동학, 운동역학적 변인의 결과는 (Table 1)과 같다. E1과 E2의 무릎관절의 굴곡각은 통계 적으로 차이가 나타나지 않았으나, E3에서 $50 \mathrm{~cm}$ 박스착 지 시 $30 \mathrm{~cm}$ 보다 굴곡각이 통계적으로 유의하게 크게 나 타났다. 외반각은 E1에서 $50 \mathrm{~cm}$ 박스착지 시 $30 \mathrm{~cm}$ 보다 통 계적으로 유의하게 크게 나타났고, E2와 E3에서는 통계 적으로 차이가 나타나지 않았다. 내회전각은 $\mathrm{E} 1$ 을 제외 하고 $\mathrm{E} 2$ 에서는 $50 \mathrm{~cm}$ 박스착지 시 $30 \mathrm{~m}$ 보다 통계적으로 유
의하게 크게 나타났고, $\mathrm{E} 3$ 에서는 $50 \mathrm{~cm}$ 박스착지 시 $30 \mathrm{~cm}$ 보다 통계적으로 유의하게 작게 나타났다. 수직지면반력 은 $50 \mathrm{~cm}$ 박스착지 시 $30 \mathrm{~cm}$ 보다 E1과 E2에서 유의하게 크 게 나타났고, E3에서는 통계적으로 차이가 나타나지 않았 다. 무릎관절의 신전모멘트는 $50 \mathrm{~cm}$ 박스착지 시 $30 \mathrm{~cm}$ 보 다 모든 시점에서 유의하게 크게 나타났다. 외반모멘트는 모든 시점에서 통계적으로 차이가 나타나지 않았다. 외 회전모멘트는 $\mathrm{E} 2$ 에서 $50 \mathrm{~cm}$ 박스착지 시 $30 \mathrm{~cm}$ 보다 통계 적으로 유의하게 크게 나타났고, E1과 E3에서는 통계적 으로 차이가 나타나지 않았다. 시상면에서의 무릎관절의 부적파워는 $50 \mathrm{~cm}$ 박스착지 시 $30 \mathrm{~cm}$ 보다 E1과 E2에서 유 의하게 크게 나타났고, E3에서는 통계적으로 차이가 나 타나지 않았다.

박스높이에 따른 근전도 변인의 차이는 (Figure 1)과 같다. 내측광근의 근활성도는 $50 \mathrm{~cm}$ 박스착지 시 $30 \mathrm{~cm}$ 보 다 $\mathrm{P} 1(\mathrm{t}=-2.548, \mathrm{p}=.020), \mathrm{P} 2(\mathrm{t}=-2.270, \mathrm{p}=.035)$ 와 $\mathrm{P} 3(\mathrm{t}=-2.451$, $\mathrm{p}=.024$ ) 전 구간에서 통계적으로 유의하게 큰 활성이 나 타났다. 외측광근의 근활성도는 $50 \mathrm{~cm}$ 박스착지 시 $30 \mathrm{~cm}$ 보다 P1(t=-3.619, $\mathrm{p}=.002)$ 와 $\mathrm{P} 2(\mathrm{t}=-4.658, \mathrm{p}=.000)$ 에서 통계 적으로 유의하게 큰 활성이 나타났고, $\mathrm{P} 3$ 에서는 통계적 으로 차이가 나타나지 않았다. 대퇴이두근의 근활성은 전 구간에서 통계적으로 차이가 나타나지 않았다. 착시 시 내측광근에 대한 대퇴이두근의 비율은 $50 \mathrm{~cm}$ 박스착지 시 $30 \mathrm{~cm}$ 보다 $\mathrm{P} 1(\mathrm{t}=4.007, \mathrm{p}=.001)$ 에서 통계적으로 유의하게 작게 나타났고, $\mathrm{P} 2$ 와 $\mathrm{P} 3$ 에서는 통계적으로 차이가 나타 지 않았다. 외측광근에 대한 대퇴이두근의 비율은 $50 \mathrm{~cm}$ 박스착지 시 $30 \mathrm{~cm}$ 보다 $\mathrm{P} 1(\mathrm{t}=3.014, \mathrm{p}=.007)$ 과 $\mathrm{P} 2(\mathrm{t}=3.259$, $\mathrm{p}=.004)$ 에서 통계적으로 유의하게 작게 나타났고, P3에서 는 통계적으로 차이가 나타지 않았다.

\section{논의}

본 연구는 박스높이 변화에 따른 박스착지시 여성축 구선수의 하지 근활성과 운동역학적 요인의 차이를 대응 t-test를 통해 검증하였다.

박스높이가 증가함에 따라 E1과 E2에서 수직지면반력 이 증가하는 것으로 나타났으나 무를 굴곡각은 차이가 없 었다. 선행연구에 의하면 뻣뺏한 착지의 형태인 감소된 무릎관절의 굴곡각과 증가된 수직지면반력은 전방십자 인대손상 발생과 관련이 있다고 보고된다[22]. 착지 시 감 속동작은 충격을 최대한 흡수하여 하지의 손상을 최소화 
Table 1. Kinematics and kinetics of the knee joint during drop landing

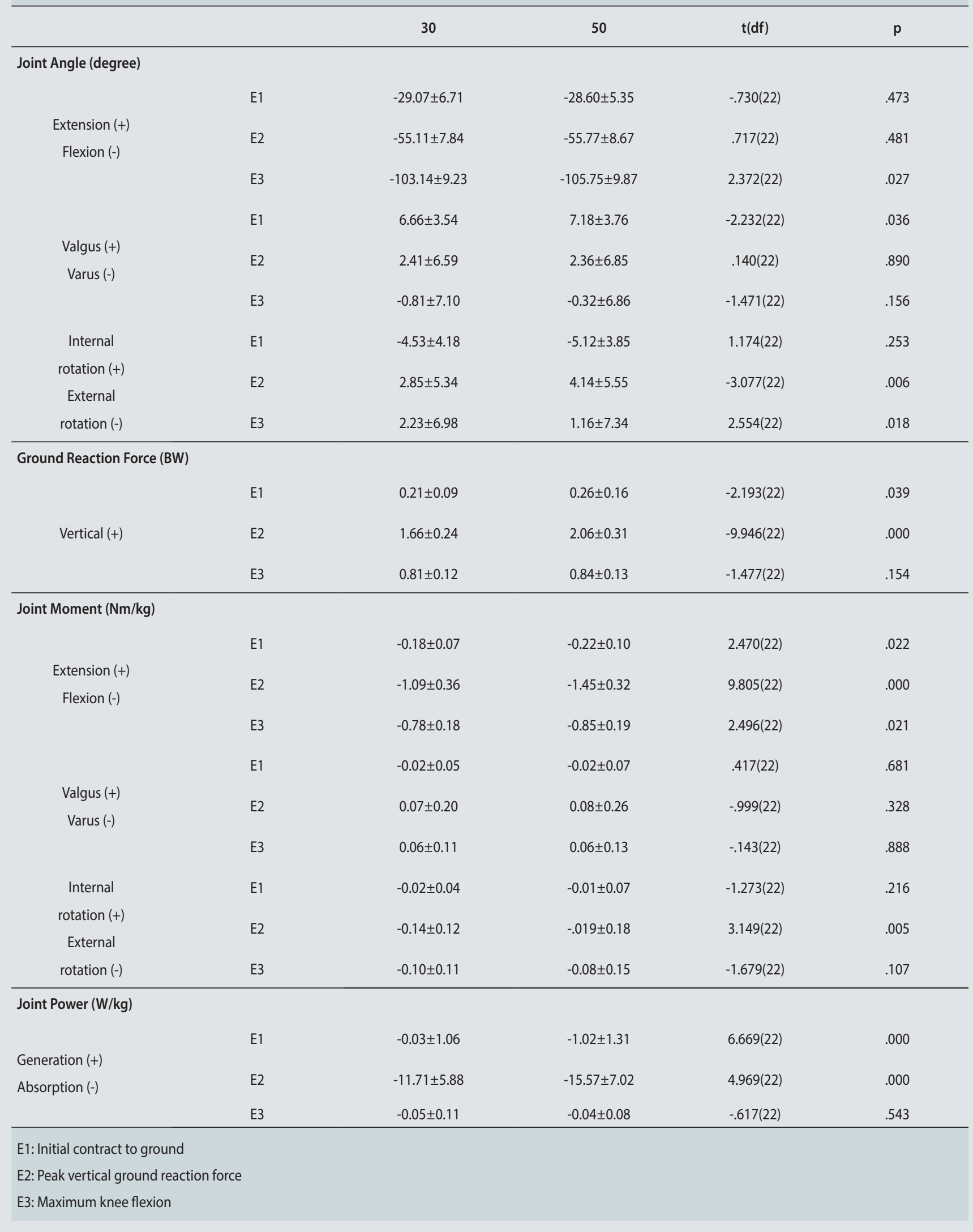




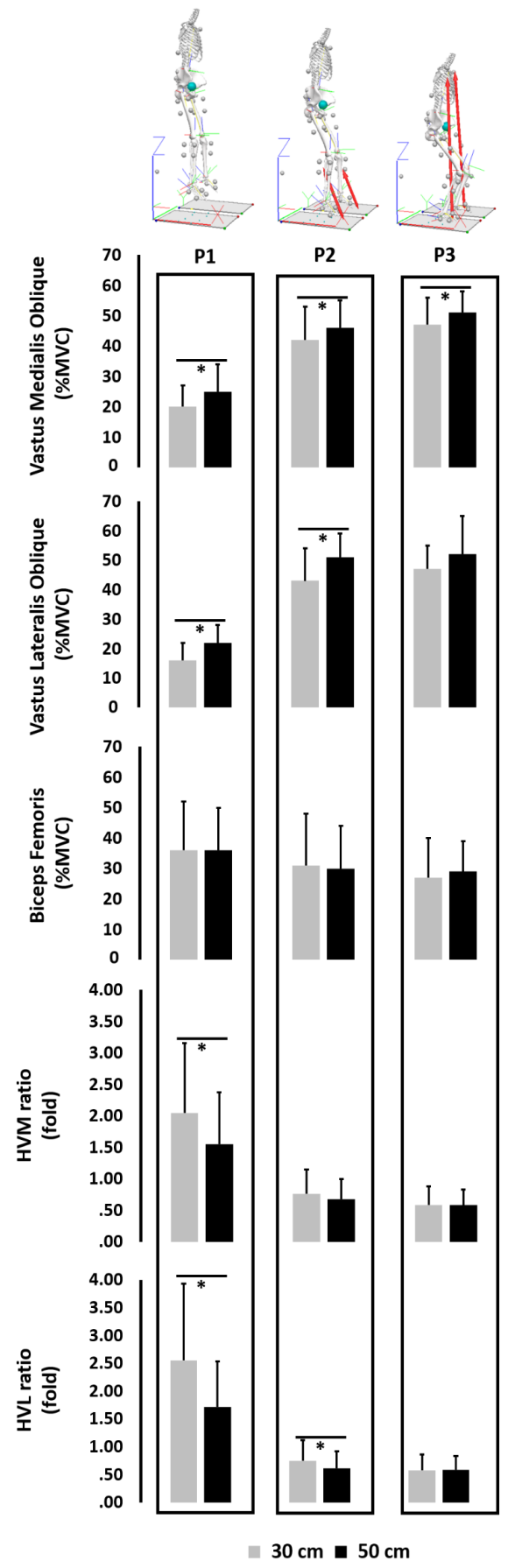

Figure 1. Muscle activation and average of hamstring to quadriceps femoris ratio during drop landing

하기 위한 전략이 요구된다. 본 연구에서는 충격흡수를 위한 전략으로 박스높이가 증가함에 따라 무릎관절의 시 상면에서 부적 관절파워와 신전모멘트가 증가하였고, 내 측광근과 외측광근의 증가된 활성이 관찰되었다. 착지 시
부적관절파워의 증가는 무를 신전근의 신장성 수축으로 충격에너지를 분산시킨다고 보고된다[23,24].

초기 착지 시 외반슬의 형태(valgus angle)는 박스높이 가 증가함에 따라 함께 증가하였다. 최대지면반력 시점 으로 넘어가면서 감소하였으나 내회전 각이 증가하는 것 으로 관찰되었다. Ford 등은 착지동작에서 여성선수의 외 반각이 남성선수 보다 큰 것으로 보고하였고, 이러한 외 반각의 증가는 관상면에서의 관절 조절능력의 감소로 무 릎손상의 위험을 증가시킬 것이라고 하였다[25]. 그러나 본 연구 결과 같은 시점에서 외회전 모멘트가 증가됨으 로써 외반슬로 자세가 무너지는 것을 방어한 전략으로 판 단된다. 또한 최대 무를 굴곡이 되는 시점에서 내회전각 은 $30 \mathrm{~cm}$ 보다 $50 \mathrm{~cm}$ 에서 착지했을 때 이전시점을 기준으 로 더 감소되는 것으로 나타났다.

내측광근과 외측광근의 근활성은 착지하는 동안 $\mathrm{E} 3$ 까 지 증가하였으나 대퇴이두근의 활성은 차이가 없었다. 선 행연구에서도 높이가 증가함에 따라 대퇴사두근의 근활 성이 증가하였으나 햄스트링의 활성은 차이가 없다고 보 고되어 본 연구의 결과와 동일한 양상을 보였다 $[15,26]$. 발 이 공중에 떠있고 무릎이 30도 굴곡 되어있는 동작에서 대퇴사두근의 수축은 발이 지면에 닿아 있을 때보다 경 골을 3 배 이상 전방전위 시키는 것으로 보고되었다[27]. 무를 굴곡각 30 도 이하일 때 햄스트링보다 대퇴사두근의 활성이 더 크면 경골의 전방전위가 나타나 전방십자인대 에 장력이 최대로 증가하는 것으로 보고되었다 $[9,28]$. 또 한 여성은 착지 $50 \mathrm{~ms}$ 전 햄스트링을 적절하게 동원하지 못하고 대퇴사두근을 주로 사용하게 됨으로써 전방십자 인대의 부하를 증가시킨다고 보고되었다[8]. 본 연구결과 $\mathrm{E} 1$ 에서 관찰된 무릎관절의 굴곡각은 30 도 이하로 $\mathrm{P} 1$ 이 경 골의 전방전단력을 증가시킬 수 있는 위험 구간으로 판단 된다. 그러나 위험구간인 P1에서 HVMratio 및 HVLratio 는 $30 \mathrm{~cm}$ 와 $50 \mathrm{~cm}$ 박스높이 모두에서 1.5 배 이상 큰 것으로 관찰되어 무릎의 안정성을 증가시킨 것으로 사료된다. 선 행연구에 의하면 대퇴사두근과 햄스트링의 동시수축은 전방십자인대에 가해지는 장력을 최대 $46 \%$ 감소시킨다 고 보고하였다[28].

본 연구결과 착지 시 대퇴이두근 근활성의 감소와 무 릎관절의 내회전 증가가 관찰되었다. 대퇴사두근에 비해 햄스트링의 근활성이 작아지면 경골의 내회전이 나타나 며, 이러한 결과는 전방십자인대 손상요인으로 보고된다 $[8,29]$. 또한 높이변화에 따른 수직지면반력의 증가와 무 
릎의 내회전의 증가는 전방십자인대 손상요인을 증가시 킬 것으로 판단된다. 따라서 무릎의 안정성을 높이기 위 한 햄스트링의 동원 및 강화 훈련을 통해 전방십자인대 방어요인을 강화시키는 것이 필요할 것으로 판단된다.

축구에서 점프, 착지, 방향전환 등은 무를의 안정성이 유지되어야 하기 때문에 준비운동프로그램의 구성을 근 신경 및 고유수용감각 훈련으로 여성축구선수에게 적용 하였을 때 전방십자인대 손상 발생률이 감소되었다[30]. 이 연구에서는 부드러운 착지(soft landing)와 엉덩, 무릎 관절의 굴곡을 깊게 하여 착지하는 전략을 강조했다. Zebis 등의 연구에서는 신체인지 향상과 운동제어에 목적 을 둔 프로그램을 20 명의 여성축구, 핸드볼 선수에 게 12 주간 적용 후 관찰한 결과 방향전환 동작에서 운동학, 운 동역학적 변화는 나타나지 않았으나 외측광근-내측햄스 트링(반건양근)의 차이가 감소하였다[31]. 위 운동프로그 램의 구성안에 신장성 수축 형 태의 햄스트링 운동(russian hamstring curl)과 종목 유사 동작을 통해 전방십자인대 손 상 예방에 전략을 제시하였으나 예방프로그램의 적용의 효율성과 효과에 대한 명확한 결과를 제시하지 못하기 때 문에 적용의 어려움이 따르고 있다. 따라서 수정된 프로 그램을 통한 적용과 검증을 지도자와 선수에 게 확신을 줄 수 있는 프로그램이 개발되어야 하며 그 내용에는 햄스트 링 강화 및 근동원률을 증가 시킬 수 있어야 하겠다.

본 연구의 제한점으로 대상자의 좌우하지가 대칭하다 는 조건하에 양발 착지동작을 실시하여 주동측만 분석하 였다. 착지동작에 따른 선수 개인의 심리적, 신체적 특성 은 고려하지 않았다.

\section{결론}

착지 시 박스높이 증가에 따라 증가된 수직지면반력, 외반각, 내회전각의 증가로 높아진 전방십자인대손상 위 험요인을 저지하기 위해 착지 시 자세를 유지하는 전략으 로 외회전 모멘트의 증가, 감속을 위한 신전모멘트와 내 측광근 및 외측광근의 근활성 증가, 충격흡수를 위한 시 상면에서의 부적 관절파워의 증가는 방어기전으로 판단 된다. 그러나 대퇴이두근의 활성은 착지동안 감소되었고 이는 경골의 전단력과 무릎관절의 내회전을 증가시킬 것 으로 판단된다. 따라서 무릎의 안정성 유지와 경골의 전 방전위를 제한하기 위해 햄스트링을 강화하는 것이 전방 십자인대 손상예방에 중요할 것으로 사료된다.
추후연구에서는 근전도를 통한 근활성뿐만 아니라 근 발현 시점 및 동시수축지수를 통해 신경근 제어에 대한 연구가 필요할 것으로 사료된다. 또한 하지의 비대칭을 고려하여 박스높이 변화에 따른 외발 착지동작을 분석할 필요가 있을 것으로 생각된다.

\section{Acknowledgements}

This study was extracted from master's thesis written by the first author.

\section{Funding}

This study was supported by the National Research Foundation of Korea Grant funded by the Korean Government (NRF-2011332-1891).

\section{Conflicts of Interest}

The authors declare no conflict of interest.

\section{References}

1. Agel J, Arendt EA, Bershadsky B. Anterior cruciate ligament injury in National Collegiate Athletic Association basketball and soccer a 13-year review. Am J Sports Med. 2005; 33(4):524-531.

2. Faunø P, Jakobsen BW. Mechanism of anterior cruciate ligament injuries in soccer. Int J Sports Med. 2006; 27(1):75-79.

3. Santello M. Review of motor control mechanisms underlying impact absorption from falls. Gait Posture. 2005; 21(1):85-94.

4. Lohmander LS, Ostenberg A, Englund M, Roos H. High prevalence of knee osteoarthritis, pain, and functional limitations in female soccer players twelve years after anterior cruciate ligament injury. Arthritis Rheum. 2004; 50(10):3145-3152.

5. Neumann DA. Kinesiology of the musculoskeletal system: Foundations for physical rehabilitation. Missouri, USA. Mosby. 2002, p 489-491. 
6. Withrow TJ, Huston LJ, Wojtys EM, Ashton-Miller JA. Effect of varying hamstring tension on anterior cruciate ligament strain during in vitro impulsive knee flexion and compression loading. J Bone Joint Surg Am. 2008; 90(4):815-823.

7. Hewett TE, Ford KR, Hoogenboom BJ, Myer GD. Understanding and preventing ACL injuries: current biomechanical and epidemiologic considerations-update 2010. N Am J Sports Phys Ther. 2010; 5(4):234251.

8. Nagano Y, Ida H, Akai M, Fukubayashi T. Gender differences in knee kinematics and muscle activity during single limb drop landing. Knee. 2007; 14(3):218223.

9. Orishimo KF, Liederbach M, Kremenic IJ, Hagins M, Pappas E. Comparison of landing biomechanics between male and female dancers and athletes, part 1: Influence of sex on risk of anterior cruciate ligament injury. Am J Sports Med. 2014; 42(5):1082-1088.

10. Myer GD, Ford KR, Barber Foss KD, Liu C, Nick TG, Hewett TE. The relationship of hamstrings and quadriceps strength to anterior cruciate ligament injury in female athletes. Clin J Sport Med. 2009; 19 (1):3-8.

11. Chappell JD, Yu B, Kirkendall DT, Garrett WE. A comparison of knee kinetics between male and female recreational athletes in stop-jump tasks. Am J Sports Med. 2002; 30(2):261-267.

12. Lephart SM, Ferris CM, Riemann BL, Myers JB, Fu FH. Gender differences in strength and lower extremity kinematics during landing. Clin Orthop Relat Res. 2002; 401:162-169.

13. Yu B, Herman D, Preston J, Lu W, Kirkendall DT, Garrett WE. Immediate effects of a knee brace with a constraint to knee extension of knee kinematics and ground reaction forces in a stop-jump task. Am J Sports Med. 2004; 32(5):1136-1143.

14. Yeow CH, Lee PV, Goh JC. Sagittal knee joint kinematics and energetics in response to different landing heights and techniques. Knee. 2010; 17(2):127-131.

15. de Britto MA, Carpes FP, Koutras G, Pappas E.
Quadriceps and hamstrings prelanding myoelectric activity during landing from different heights among male and female athletes. J Electromyogr Kinesiol. 2014; 24(4):508-512.

16. Walsh M, Boling MC, McGrath M, Blackburn JT, Padua DA. Lower extremity muscle activation and knee flexion during a jump-landing task. J Athl Train. 2012; 47(4):406-413.

17. Myer GD, Ford KR, Khoury J, Succop P, Hewett TE. Biomechanics laboratory-based prediction algorithm to identify female athletes with high knee loads that increase risk of ACL injury. Br J Sports Med. 2011; 45 (4):245-252.

18. Ford KR, Myer GD, Hewett TE. Reliability of landing 3D motion analysis: implications for longitudinal analyses. Med Sci Sports Exerc. 2007; 39(11):20212028.

19. Sell TC, Ferris CM, Abt JP, et al. Predictors of proximal tibia anterior shear force during a vertical stopjump. J Orthop Res. 2007; 25(12):1589-1597.

20. Medina JM, Valovich McLeod TC, Howell SK, Kingma JJ. Timing of neuromuscular activation of the quadriceps and hamstrings prior to landing in high school male athletes, female athletes, and female non-athletes. J Electromyogr Kinesiol. 2008; 18(4):591-597.

21. Arampatzis A, Morey-Klapsing G, Brüggemann GP. The effect of falling height on muscle activity and foot motion during landings. J Electromyogr Kinesiol. 2003; 13(6):533-544.

22. Leppänen M, Pasanen K, Kujala UM, et al. Stiff landings are associated with increased ACL injury risk in young female basketball and floorball players. Am J Sports Med. 2017; 45(2):386-393.

23. Yeow CH, Lee PV, Goh JC. Regression relationships of landing height with ground reaction forces, knee flexion angles, angular velocities, and joint powers during double-leg landing. Knee. 2009; 16(5):381-386.

24. Zhang SN, Bates BT, Dufek J. Contributions of lower extremity joints to energy dissipation during landings. Med Sci Sports Exerc. 2000; 32(4):812-819.

25. Ford KR, Myer GD, Hewett TE. Valgus knee mo- 
tion during landing in high school female and male basketball players. Med Sci Sports Exerc. 2003; 35 (10):1745-1750.

26. Ford KR, Myer GD, Schmitt LC, Uhl TL, Hewett TE. Preferential quadriceps activation in female athletes with incremental increases in landing intensity. J Appl Biomech. 2011; 27(3):215-222.

27. Jenkins WL, Munns SW, Jayaraman G, Wertzberger KL, Neely K. A measurement of anterior tibial displacement in the closed and open kinetic chain. J Orthop Sports Phys Ther. 1997; 25(1):49-56.

28. Li G, Rudy TW, Sakane M, Kanamori A, Ma CB, Woo SL. The importance of quadriceps and hamstring muscle loading on knee kinematics and in-situ forces in the ACL. J Biomech. 1999; 32(4):395-400.
29. Koga H, Nakamae A, Shima Y, et al. Mechanisms for noncontact anterior cruciate ligament injuries knee joint kinematics in 10 injury situations from female team handball and basketball. Am J Sports Med. 2010; 38(11):2218-2225.

30. Mandelbaum BR, Silvers HJ, Watanabe DS, et al. Effectiveness of a neuromuscular and proprioceptive training program in preventing anterior cruciate ligament injuries in female athletes: 2-year follow-up. Am J Sports Med. 2005; 33(7):1003-1010.

31. Zebis MK, Andersen LL, Brandt M, et al. Effects of evidence-based prevention training on neuromuscular and biomechanical risk factors for ACL injury in adolescent female athletes: a randomised controlled trial. Br J Sports Med. 2016; 50(9):557-559. 